\title{
Room temperature hydrolysis of benzamidines and benzamidiniums in weakly basic water
}

\author{
Li-Juan Yu, Duncan A. Cullen, Mahbod Morshedi, Michelle L. Coote, ${ }^{*}$ and Nicholas G. White* \\ Benzamidinium compounds have found widespread use in both medicinal and supramolecular chemistry. In this work, we show that \\ benzamidiniums hydrolyse at room temperature in aqueous base to give the corresponding primary amide. This reaction has a half-life of 300 \\ days for unsubstituted benzamidinium at $\mathrm{pH}$ 9, but is relatively rapid at higher pHs (e.g. $\mathrm{t}_{1 / 2}=6$ days at $\mathrm{pH} 11$ and 15 hours at $\mathrm{pH} 13$ ). Quantum \\ chemistry combined with first principles kinetic modelling can reproduce these trends and explain them in terms of the dominant pathway being \\ initiated by attack of $\mathrm{HO}^{-}$on benzamidine. Incorporation of the amidinium motif into a hydrogen bonded framework offers a substantial protective \\ effect against hydrolysis.
}

\section{Introduction}

Compounds based on benzamidine or protonated benzamidinium functional groups are used in a wide range of biological and medicinal chemistry applications, and are seeing increasing use in supramolecular chemistry. ${ }^{1,2}$ The high basicity of amidine and benzamidine derivatives means that they are protonated under physiological conditions and as a result have high water solubility, but potentially low bioavailability.

Numerous drug molecules contain some form of amidine/amidinium functionality, and many are based on benzamidinium groups. ${ }^{3}$ Indeed, unsubstituted benzamidinium is an effective trypsin inhibitor, ${ }^{4}$ and several benzamidinium molecules have been developed as reversible serine protease inhibitors, acting by hydrogen bonding to a carboxylate residue in the enzymes' active site. ${ }^{3,5,6}$ A wide range of drug molecules containing two benzamidinium moieties attached through simple linker groups are available, perhaps most notably pentamidine (Figure 1), ${ }^{7,} 8$ which is a World Health Organization Essential Medicine used for treatment of protozoan infections.

Benzamidinium groups have also proven useful in supramolecular chemistry, both in the context of hostguest chemistry and in self-assembly. Early studies by Nocera, ${ }^{9}$ Gale $^{10,11}$ and Diederich ${ }^{12,13}$ demonstrated that strong interactions were possible between the benzamidinium group and carboxylates in solution (including polar organic solvents and water), and these and similar interactions have subsequently been used to prepare a range of self-assembled structures. Notably, Crego-Calama's group pioneered the development of capsules based on benzamidinium $\cdots$ carboxylate and benzamidinium $\cdots$ sulfonate interactions, ${ }^{14,15}$ and Yashima has developed a range of structures including catenanes, helices and capsules assembled via benzamidinium $\cdots$ carboxylate hydrogen bonds. ${ }^{16-19}$ More recently, our group ${ }^{20-22}$ and the groups of Ben and Comotti 23,24 have demonstrated that benzamidinium groups can be used to form hydrogen bonded frameworks with carboxylate and sulfonate anions.

Given the relevance of these functional groups in both medicinal and supramolecular chemistry, it is important to understand their stability. Lewis and Wolfenden have completed a detailed study of the decomposition of alkylamidine and alkylguanidine derivatives at elevated temperatures: they showed that decomposition in water occurred via hydrolysis rather than elimination. Importantly, protonation of the neutral amidine/guanidine species dramatically slowed decomposition. ${ }^{25} \mathrm{We}$ also note that commercially-available benzamidinium chloride is noted by at least one manufacturer to be sensitive to oxidation in aqueous solution. ${ }^{26}$

In certain circumstances, we have isolated amidecontaining products when starting from benzamidiniums. In this report, we investigate the hydrolysis of benzamidiniums at room temperature. We show that while the rate of hydrolysis is negligible at neutral $\mathrm{pH}$, it becomes significant under mildly basic conditions and rapid in strong aqueous base (e.g. $\mathrm{t}_{1 / 2}=15 \mathrm{hrs}$ at room temperature at $\mathrm{pH}$ 13). We do not observe any evidence for oxidation, even upon standing for extended periods in $\mathrm{O}_{2}$-saturated $\mathrm{D}_{2} \mathrm{O}{ }^{27}$

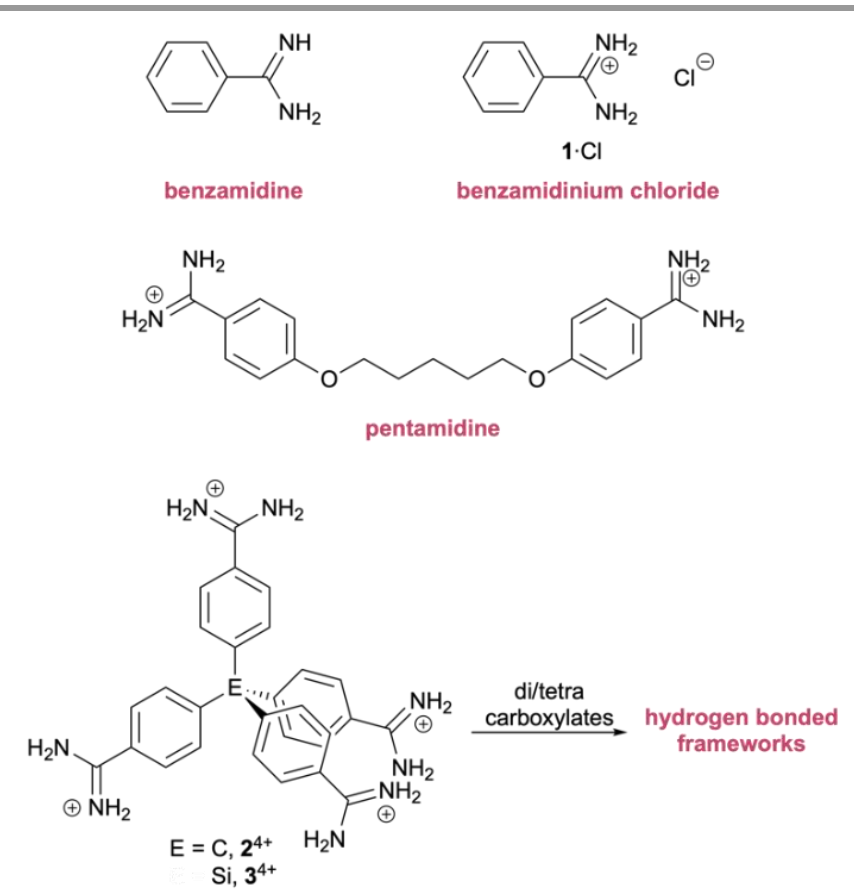

Figure 1 Structure of benzamidine, benzamidinium, and pentamidine, and diagram showing the use of poly-amidiniums to prepare hydrogen bonded frameworks. 


\section{Results and discussion}

Isolation of tetra-amides from tetra-amidinium crystallisations: Our group has prepared a range of hydrogen bonded frameworks from benzamidinium and carboxylate tectons. We typically prepare the tetrabutylammonium (TBA) salts of the carboxylates and use these in the reaction, however we were interested to see whether it was possible to directly use the carboxylic acids and deprotonate in situ using an aqueous base such as $\mathrm{NaOH}$ or $\mathrm{NH}_{3}$. In many cases, this is possible, and indeed we have used this methodology when encapsulating enzymes within our hydrogen bonded frameworks. ${ }^{28}$ However, when we tried to make frameworks from the tetra-amidinium $\mathbf{2}^{4+}$ and anthracenedicarboxylate or bromoterephthalate in this way, ${ }^{29}$ we obtained single crystals not of the desired hydrogen bonded frameworks but of the tetraamide compound 4 (Figure 2). Similarly, when we attempted to prepare frameworks from the silicon-centred tetra-amidinium $3^{4+}$ and bicarbonate, we sometimes obtained crystals of the silicon tetra-amide 5. It was notable that in both of these cases, crystallization took a long time (several days). In fact in the case of the silicon-based system, if we used higher concentrations, crystallization occurred more rapidly and we did not obtain the tetra-amide $\mathbf{5}$, but instead obtained a hydrogen bonded salt of the tetra-amidinium. ${ }^{30}$

The crystal structures of $\mathbf{4}$ and $\mathbf{5}$ are isostructural and crystallize in the tetragonal space group $P 4_{2} / n$. The structures assemble through $\mathrm{N}-\mathrm{H} \cdots \mathrm{O}=\mathrm{C}$ amide $\cdots$ amide hydrogen bonds, which have a double helical arrangement (Figure 2). While related systems based on self-complementary hydrogen bonds and tetraphenylmethane or tetraphenylsilane components form large solvent-filled channels, ${ }^{31-33} \mathbf{4}$ and $\mathbf{5}$ are close-packed and do not contain any solvent. Attempts to synthesize bulk $\mathbf{4}$ or $\mathbf{5}$ by standing $\mathbf{2} \cdot \mathrm{Cl}_{4}$ or $\mathbf{3} \cdot \mathrm{Cl}_{4}$ in aqueous base did not result in clean conversion; the solid products appeared to be contaminated with amidine derivatives, i.e. on a bulk scale precipitation occurs before complete conversion to the amide.

NMR study of hydrolysis of benzamidinium: To gain an understanding of the decomposition process, we initially investigated the hydrolysis of benzamidinium chloride $(\mathbf{1} \cdot \mathbf{C l})$ using ${ }^{1} \mathrm{H}$ NMR experiments in $\mathrm{D}_{2} \mathrm{O}$. We initially studied what happened when $1 \cdot \mathrm{Cl}$ was exposed to the relatively weak bases, sodium hydrogencarbonate and sodium carbonate. After $24 \mathrm{hrs}$ in the presence of one equivalent of $\mathrm{Na}_{2} \mathrm{CO}_{3}$, approximately $15 \%$ of the benzamidinium cation had been hydrolysed to give benzamide, rising to approximately $50 \%$ after eight days. When only $10 \mathrm{~mol} \% \mathrm{Na}_{2} \mathrm{CO}_{3}$ was present, hydrolysis was slower with only $6 \%$ hydrolysis within 24 hours and $20 \%$ hydrolysis after eight days. In contrast hydrolysis was very slow when $\mathrm{NaHCO}_{3}$ was used (approximately 10\% hydrolyzed after three weeks in the presence of four equivalents of $\mathrm{NaHCO}_{3}$ ).

Given the apparent dependence on $\mathrm{pH}$, we next studied hydrolysis of $\mathbf{1 .} \mathbf{C I}$ in deuterated buffers. At $\mathrm{pH} 10$, negligible hydrolysis was observed in the first few hours and after 30 hours, less than $2 \%$ of $\mathbf{1}^{+}$had been hydrolyzed. Increasing $\mathrm{pH}$ dramatically increased the rate of hydrolysis, with $11 \%$ of $1^{+}$ hydrolyzed after 30 hours at $\mathrm{pH} 11$, and $36 \%$ of $\mathbf{1}^{+}$hydrolyzed after 30 hours at $\mathrm{pH} 12$ (Figure 3). Rate constants for these reactions are provided in Table 1 , as well as rate constants in aqueous hydroxide $(0.10$ or $1.0 \mathrm{M})$, which are faster again. Interestingly the rate does not increase substantially on going from 0.10 to $1.0 \mathrm{M} \mathrm{NaOH}_{(\mathrm{aq})}$, and these rates are only slightly faster than phosphate buffer at $\mathrm{pH}=12$.

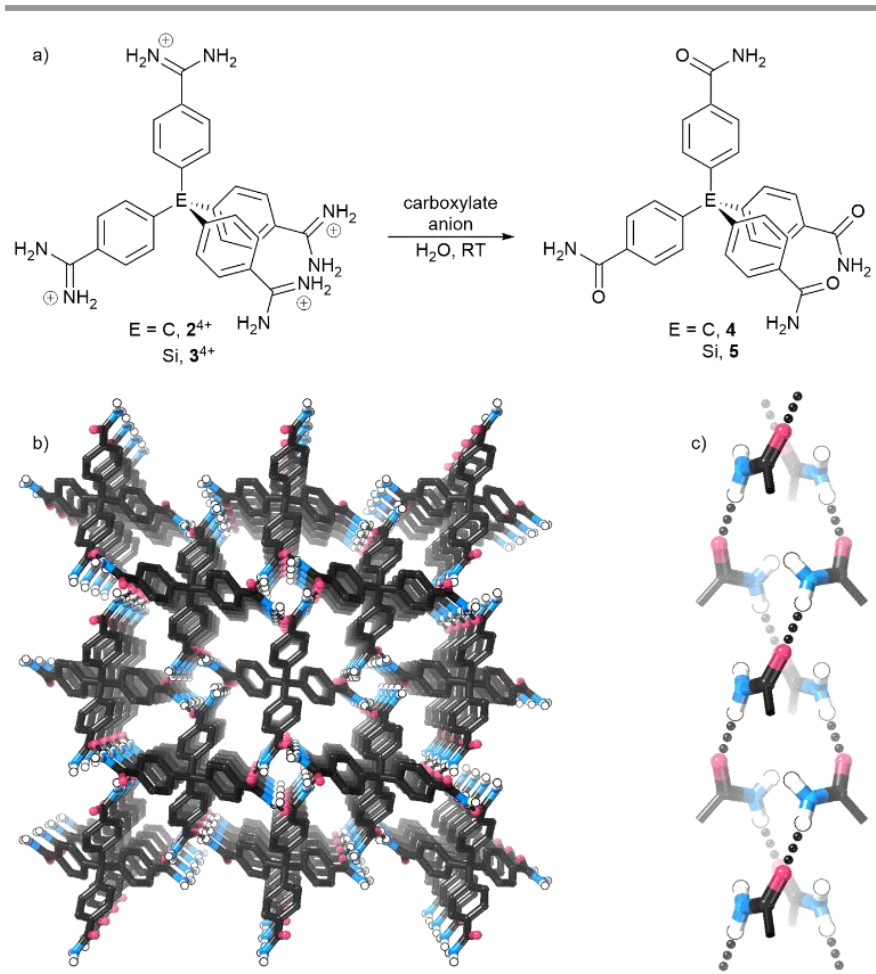

Figure 2 a) Conversion of tetra-amidiniums to single crystals of tetra-amides; b) diagram showing packing in crystal structure of $4(\mathrm{C}-\mathrm{H}$ hydrogen atoms omitted for clarity), c) diagram showing double helical hydrogen bonding arrangement in crystal structure of $\mathbf{4}$. The structure of $\mathbf{5}$ is isostructural with $\mathbf{4}$ (Figures S3 and S4).

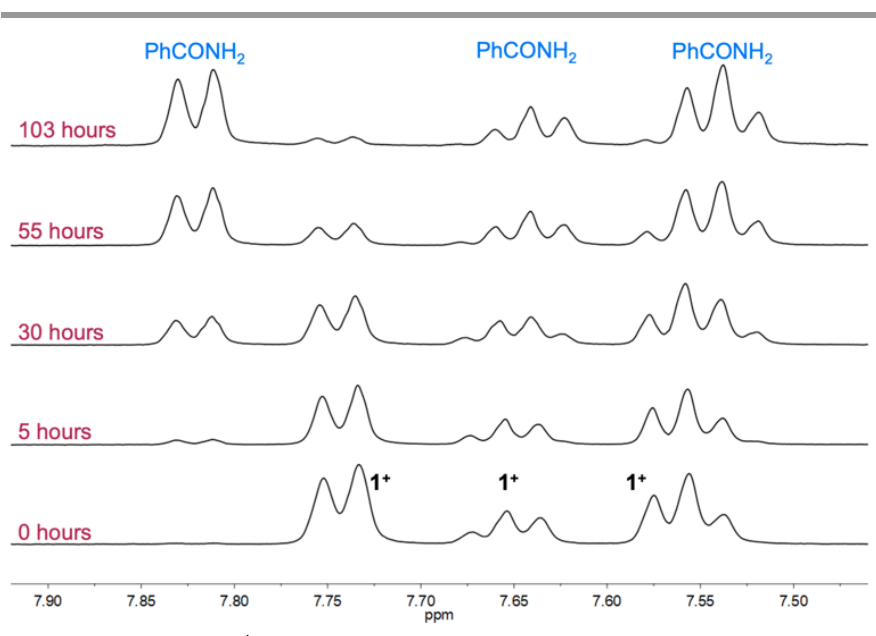

Figure 3 Truncated ${ }^{1} \mathrm{H}$ NMR spectra showing conversion of $\mathbf{1}^{+}$to benzamide (10 mM 1. $\mathrm{Cl}$ in $100 \mathrm{mM}$ phosphate buffer at $\mathrm{pH}=12$ in $\mathrm{D}_{2} \mathrm{O}, 400 \mathrm{MHz}, 298 \mathrm{~K}$ ). 
Table 1 Rate constants for hydrolysis of $\mathbf{1} \cdot \mathbf{C l}$.

\begin{tabular}{ccc}
\hline Condition & Rate constant, $\boldsymbol{k}\left(\mathbf{s}^{-1}\right)^{\mathbf{a}}$ & $\mathbf{t}_{\mathbf{1 / 2}}$ \\
\hline Buffer, $^{\mathrm{b}} \mathrm{pH}=9$ & $2.7(6) \times 10^{-8}$ & 300 days \\
Buffer, $^{\mathrm{b}} \mathrm{pH}=10$ & $1.7(2) \times 10^{-7}$ & 47 days \\
Buffer, $^{\mathrm{b}} \mathrm{pH}=11$ & $1.3(1) \times 10^{-6}$ & 6 days \\
Buffer, $^{\mathrm{b}} \mathrm{pH}=12$ & $6.0(2) \times 10^{-6}$ & $32 \mathrm{hrs}$ \\
$0.10 \mathrm{M} \mathrm{NaOH}$ & $1.3(1) \times 10^{-5}$ & $15 \mathrm{hrs}$ \\
initial pH $=13$ & & \\
$1.0 \mathrm{M} \mathrm{NaOH}$ & & $14 \mathrm{hrs}$ \\
initial pH $=14$ & &
\end{tabular}

a Estimated standard errors of the regression are given in parentheses. ${ }^{\mathrm{b}} 10 \mathrm{mM}$ $1 \cdot \mathrm{Cl}, 100 \mathrm{mM}$ phosphate buffer in $\mathrm{D}_{2} \mathrm{O} .{ }^{c} 10 \mathrm{mM} 1 \cdot \mathrm{Cl}$ and $\mathrm{NaOH}$ in $\mathrm{D}_{2} \mathrm{O}$.

Computational Study. To understand the $\mathrm{pH}$-dependence of the hydrolysis rate, density functional theory calculations were performed at the M062X/Def2-TZVP//M06-2X/6$31+G(d, p)$ level of theory using an SMD-based cluster continuum model to take into account solvent effects in water. A previous theoretical study of this substrate only considered reactions with water, ${ }^{34}$ though experimental ${ }^{25}$ and computational ${ }^{35}$ studies of related substrates suggest $\mathrm{HO}^{-}$attack is likely to be involved, at least at some $\mathrm{pH}$ values.

Thus, in the present work five pathways were considered corresponding to initial attack by either $\mathrm{HO}^{-}$or $\mathrm{H}_{2} \mathrm{O}$ on either benzamidinium or benzamidine. In the latter case, two different pathways for $\mathrm{HO}^{-}$attack were considered, one of which involves a subsequent $\mathrm{H}^{+}$attack during the hydrolysis and is labelled $\mathrm{HO}^{-} / \mathrm{H}^{+}$. For each pathway, pseudo first order rate coefficients were calculated as a function of $\mathrm{pH}$ using analytical steady state kinetic models, that were derived based on the reasonable assumption that the final step in the process was irreversible, and that the concentrations of $\left[\mathrm{HO}^{-}\right]$and $\left[\mathrm{H}^{+}\right]$ remained constant. Full methodological details and results are provided in the SI (the individual steps in each pathway are shown in Scheme S1). Table 2 provides the rate coefficients for each pathway as a function of $\mathrm{pH}$, as well as the overall weighted rate coefficient, weighted by the speciation of benzamidinum versus benzamidine at each $\mathrm{pH}$, as calculated using the experimental $\mathrm{p} K_{\mathrm{a}}$ of benzamidinium (11.6). ${ }^{36}$

The dominant pathway involves $\mathrm{HO}^{-}$attack on the benzamidine, and even at low $\mathrm{pH}$ where the benzamidine concentration is 400 times smaller than the benzamidinium, the hydrolysis of benzamidine still makes the major contribution to the weighted rate coefficient. The low $\mathrm{pH}$ sensitivity of this dominant pathway stems from the fact that the first step involves attack by $\mathrm{HO}^{-}$but a subsequent step involves protonation, resulting in a rate coefficient for benzamidine is that is largely $\mathrm{pH}$ independent. The $\mathrm{pH}$ dependence of overall hydrolysis rate is governed largely by the $\mathrm{pH}$ dependence of the benzamidinium:benzamidine speciation. As a result, we predict computationally a smooth decrease in half-life as $\mathrm{pH}$ increases, and these results agree well with experiment (Figure 4).

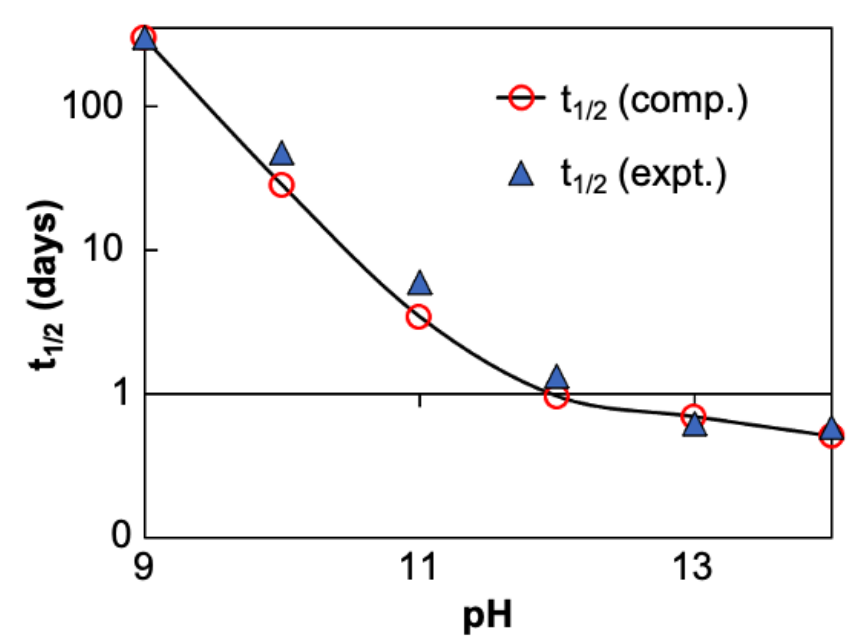

Figure 4 Comparison of computational and experimental half-lives for hydrolysis of $1 \cdot \mathrm{Cl}$.

Table 2 Computed pseudo-first order rate constants for hydrolysis of $\mathbf{1}^{+} .^{\text {a }}$

\begin{tabular}{|c|c|c|c|c|c|c|c|c|}
\hline \multirow{3}{*}{ pH } & \multirow{3}{*}{$\frac{[\text { benzamidine }]}{[\text { benzamidinium }]}$} & \multicolumn{6}{|c|}{ Rate constant, $k\left(s^{-1}\right)$} & \multirow{3}{*}{ half-life } \\
\hline & & \multicolumn{2}{|c|}{ benzamidinium } & \multicolumn{3}{|c|}{ benzamidine } & \multirow{2}{*}{ overall } & \\
\hline & & $\mathrm{H}_{2} \mathrm{O}$ & $\mathrm{HO}^{-}$ & $\mathrm{H}_{2} \mathrm{O}$ & $\mathrm{HO}^{-}$ & $\mathrm{HO}^{-} / \mathrm{H}^{+}$ & & \\
\hline 9 & $2.51 \times 10^{-3}$ & $8.22 \times 10^{-12}$ & $5.27 \times 10^{-12}$ & $1.91 \times 10^{-20}$ & $4.29 \times 10^{-11}$ & $1.09 \times 10^{-5}$ & $2.73 \times 10^{-8}$ & 294 days \\
\hline 10 & $2.51 \times 10^{-2}$ & $2.61 \times 10^{-11}$ & $5.27 \times 10^{-11}$ & $1.91 \times 10^{-20}$ & $4.29 \times 10^{-10}$ & $1.16 \times 10^{-5}$ & $2.84 \times 10^{-7}$ & 28 days \\
\hline 11 & $2.51 \times 10^{-1}$ & $3.34 \times 10^{-11}$ & $5.27 \times 10^{-10}$ & $1.91 \times 10^{-20}$ & $4.29 \times 10^{-9}$ & $1.17 \times 10^{-5}$ & $2.34 \times 10^{-6}$ & 82 hrs \\
\hline 12 & 2.51 & $3.43 \times 10^{-11}$ & $5.27 \times 10^{-9}$ & $1.91 \times 10^{-20}$ & $4.29 \times 10^{-8}$ & $1.17 \times 10^{-5}$ & $8.38 \times 10^{-6}$ & $23 \mathrm{hrs}$ \\
\hline 14 & 251 & $3.44 \times 10^{-11}$ & $5.27 \times 10^{-7}$ & $1.91 \times 10^{-20}$ & $4.29 \times 10^{-6}$ & $1.17 \times 10^{-5}$ & $1.59 \times 10^{-5}$ & $12 \mathrm{hrs}$ \\
\hline
\end{tabular}

a Calculated using quantum-chemical predicted rate and equilibrium coefficients for the individual steps in each hydrolysis pathway shown in Scheme $\mathrm{S} 1$ of the Supporting Information. The solution was assumed to be buffered at the specified pH for all calculations. The overall rate coefficient for hydrolysis is calculated as a weighted sum of those for benzamidinium and benzamidine, weighted by their speciation at the given $\mathrm{pH}$. 
NMR study of hydrolysis of poly-amidiniums: We were interested to see how charge affects the rate of hydrolysis of polycationic species such as $2^{4+}$ and the bis-amidinium $6^{2+}$. Unfortunately, it was not possible to study $\mathbf{2}^{4+}$ or $\mathbf{6}^{2+}$ in phosphate buffer, as they did not dissolve, which we attribute to the formation of insoluble (hydrogen)phosphate-containing networks. The same thing was observed when we attempted to use carbonate as base to study the hydrolysis of $2^{4+}$, which we attribute to a similar phenomenon. The compounds $2^{4+}$ and $6^{2+}$ also did not dissolve in aqueous sodium hydroxide, which we attribute to formation of the insoluble bis/tetra-amidines. ${ }^{37}$

Using $1 \% \mathrm{NH}_{3}$ in $\mathrm{D}_{2} \mathrm{O}$, we were able to study the hydrolysis of $\mathbf{1}^{+}, \mathbf{2}^{4+}$ and $\mathbf{6}^{2+}$. When $\mathbf{1}^{+}$was studied, all species stay in solution; however hydrolysis of $2^{4+}$ and $6^{2+}$ gives insoluble products, so we studied the disappearance of the starting material against a 1,4-dioxane standard. The rate of hydrolysis of $1^{+}$in this solvent was $1.7(1) \times 10^{-6} \mathrm{~s}^{-1}$, i.e. between the rates of buffer at $\mathrm{pH} 11$ and 12, as would be expected given the $\mathrm{pH}$ of $1 \% \mathrm{NH}_{3}$ in $\mathrm{D}_{2} \mathrm{O}(\sim 11.5)$. Both the bis-amidinium $\mathbf{6}^{2+}$ and tetraamidinium $2^{4+}$ hydrolyzed more rapidly than $1^{+}$, by a factor of approximately four for $6^{2+}$ and three for $2^{4+}$ (Table 2). These systems are not directly comparable with one another, as both amidinium moieties are attached to the same benzene ring in $6^{2+}$, while in $2^{4+}$ the four amidinium moieties are on separate rings. Nevertheless, it is clear that poly-amidinium compounds hydrolyze more rapidly than simple $\mathbf{1}^{+}$.

Table 3 Rate constants for hydrolysis amidinium species in $1 \% \mathrm{NH}_{3(\mathrm{aq}) .}{ }^{\mathrm{a}}$

\begin{tabular}{ccc}
\hline Compound & Rate constant, $\boldsymbol{k}\left(\mathbf{s}^{-1}\right)^{\mathbf{a}}$ & $\mathbf{t}_{\mathbf{1 / 2}}$ \\
\hline $\mathbf{1} \cdot \mathbf{C l}$ & $1.7(1) \times 10^{-6}$ & 5 days \\
$\mathbf{2} \cdot \mathbf{C l}_{\mathbf{4}}$ & $5.4(2) \times 10^{-6}$ & $36 \mathrm{hrs}$ \\
$\mathbf{6} \cdot \mathbf{C l}_{\mathbf{2}}$ & $6.6(3) \times 10^{-6}$ & $29 \mathrm{hrs}$
\end{tabular}

a All compounds $10 \mathrm{mM}, 1 \% \mathrm{NH}_{3}$ is approximately $540 \mathrm{mM}$ and has a $\mathrm{pH}$ of approximately 11.5. ${ }^{b}$ Estimated standard errors of the regression are given in parentheses.

NMR study of hydrolysis of amidinium carboxylate frameworks: We were interested to see how robust amidinium $\cdots$ carboxylate frameworks are in the present of base. We have previously demonstrated that enzymes encapsulated in frameworks are stable at $\mathrm{pH} 4-10$, but decompose at $\mathrm{pH}$ $14 .^{28}$ We also only observed formation of 4 from $2^{4+}$ when crystals of the amidinium $\cdots$ carboxylate framework did not form rapidly - both of which suggest that crystallization may offer some form of protection against hydrolysis. To study this, we studied two hydrogen bonded frameworks: a 2D material formed from $6^{2+}$ and terephthalate, ${ }^{38,} 39$ and a 3D network formed from $\mathbf{2}^{4+}$ and tetrakis(4-carboxyphenyl)methane ${ }^{20}$ (see Supporting Information for structures).

Suspensions of these frameworks $(10 \mathrm{mM})$ in $1 \% \mathrm{NH}_{3}$ in $\mathrm{D}_{2} \mathrm{O}$ were stored at room temperature for seven days, and monitored by ${ }^{1} \mathrm{H}$ NMR spectroscopy. If the amidinium compound decomposed, it would be expected that this would release the carboxylate into aqueous solution, however negligible leaching of any organic compounds into solution was observed. After seven days, the suspensions were filtered and the solid material analyzed by powder X-ray diffraction (PXRD), which revealed that both frameworks remained crystalline during this treatment (Figures S42 and S43). The solid materials were digested with $\mathrm{DCl}_{(\mathrm{aq})}$, dissolved in $\mathrm{d}_{6}-\mathrm{DMSO}$ and analyzed by ${ }^{1} \mathrm{H}$ NMR spectroscopy. This revealed negligible decomposition for the framework assembled from $6^{2+}$, and minimal ( 5\%) decomposition for the framework prepared from $\mathbf{2}^{4+}$. It appears that incorporation into a solid state framework offers a significant protective effect, given that free $6^{2+}$ and $2^{4+}$ are $>95 \%$ hydrolyzed within one week. When the frameworks were suspended in $100 \mathrm{mM} \mathrm{NaOH}_{(\mathrm{aq})}$ (i.e. a starting $\mathrm{pH}$ of 13), significant decomposition was observed.

\section{Conclusions}

Benzamidinium containing molecules hydrolyze relatively rapidly at room temperature in weakly basic water, but do not appear to oxidize under these conditions. The rate of hydrolysis increases with increasing $\mathrm{pH}$, primarily due to the effect of $\mathrm{pH}$ on the protonation state of the benzamidinium. DFT calculations combined with kinetic modelling reproduces the experimental results and indicates that the dominant pathway over the $\mathrm{pH}$ range studied ( $\mathrm{pH} 9-14$ ) is $\mathrm{HO}^{-}$attack on the benzamidine, followed by protonation of the intermediate species prior to hydrolysis. This individual pathway has a rate coefficient that is largely $\mathrm{pH}$ independent, but its rate declines with decreasing $\mathrm{pH}$ as benzamidine is increasingly protonated into its less reactive benzamidinium form. As a result, incorporating benzamidinium groups into a hydrogen bonded framework offers significant protection against hydrolysis.

\section{Experimental Section}

Benzamidinium chloride hydrate was recrystallized from $1.0 \mathrm{M} \mathrm{HCl}_{(\mathrm{aq})}$ before use. ${ }^{40}$ Characterization by $\mathrm{X}$-ray crystallography revealed that crystals fresh from the mother liquor were the dihydrate, while thermogravimetric analysis indicated that the dried product was the monohydrate (see Supporting Information). The tetraamidinium compounds $2^{4+22}$ and $3^{4+30}$ and the bisamidinium $6^{2+38}$ were prepared as previously described, as were the hydrogen bonded frameworks assembled from $6^{2+}$ and terephthalate, ${ }^{39}$ and from $2^{4+}$ and tetrakis(4carboxyphenyl)methane..$^{20}$ Other compounds were bought from commercial suppliers and used as received.

\section{Computational methods}

All the geometry optimizations and single point energy calculations were performed with the Gaussian 16 software package. ${ }^{41}$ Geometries were optimized in water at the M06$2 X / 6-31+G(d, p)$ level of theory ${ }^{42}$ with SMD solvent model, ${ }^{43}$ and 
frequencies were also calculated at this level. Geometries were verified either as local minima (possessing no imaginary frequencies) or transition states (possessing only one imaginary frequency). Entropies, thermal corrections, and zeropoint vibrational energies were calculated using frequencies scaled by the recommended scaling factors based on solution phase optimized geometries. ${ }^{44}$ Improved single-point energies in gas phase were calculated using the Def2-TZVP basis set ${ }^{45}$ with the same DFT functional. Reported Gibbs free energies in solution at $298 \mathrm{~K}$ were obtained via a thermocycle method in which electronic energy in gas phase at M062X/Def2-TZVP, was combined with entropies, thermal corrections, and zeropoint vibrational energies at $M 062 X / 6-31+G(d, p)$, solvation energies calculated at M062X/6-31+G(d,p) with SMD solvent model and the necessary phase change correction term. ${ }^{46}$

\section{Acknowledgements}

We thank the Australian Research Council for financial support (DE170100200 and FL170100041), the National Computational Infrastructure for supercomputing time, and Drs Lara Malins and Tristan Reekie (Australian National University) for helpful discussions.

\section{References}

1. Yashima, E.; Maeda, K.; Furusho, Y., Single- and Double-Stranded Helical Polymers: Synthesis, Structures, and Functions. Acc. Chem. Res. 2008, 41, 1166-1180.

2. White, N. G., Recent advances in self-assembled amidinium and guanidinium frameworks. Dalton Trans. 2019, 48, 7062-7068.

3. Greenhill, J. V.; Lue, P., 5. Amidines and Guanidines in Medicinal Chemistry, in Prog. Med. Chem., Ellis, G. P.; Luscombe, D. K., Eds. Elsevier: 1993; Vol. 30, pp 203326.

4. Mares-Guia, M.; Shaw, E., Studies on the Active Center of Trypsin: The Binding of Amidines and Guanidines as Models of the Substrate Side Chain, J. Biol. Chem. 1965, 240, 1579-1585.

5. Giovanni, A.; David, P. F., Protease Inhibitors in the Clinic. Med. Chem. 2005, 1, 71-104.

6. Schiebel, J.; Gaspari, R.; Wulsdorf, T.; Ngo, K.; Sohn, C.; Schrader, T. E.; Cavalli, A.; Ostermann, A.; Heine, A.; Klebe, G., Intriguing role of water in protein-ligand binding studied by neutron crystallography on trypsin complexes. Nature Commun. 2018, 9, 3559.

7. Bray, P. G.; Barrett, M. P.; Ward, S. A.; de Koning, H. P., Pentamidine uptake and resistance in pathogenic protozoa: past, present and future. Trends Parasitol. 2003, 19, 232-239.

8. Soeiro, M. N. C.; Werbovetz, K.; Boykin, D. W.; Wilson, W. D.; Wang, M. Z.; Hemphill, A., Novel amidines and analogues as promising agents against intracellular parasites: a systematic review. Parasitology 2013, 140, 929-951.

9. Deng, Y.; Roberts, J. A.; Peng, S.-M.; Chang, C. K.; Nocera, D. G., The Amidinium-Carboxylate Salt Bridge as a Proton-Coupled Interface to Electron Transfer Pathways. Angew. Chem. Int. Ed. 1997, 36, 2124-2127.
10. Gale, P. A., Bis-amidinium calixarenes: Templates for self-assembled receptors. Tetrahedron Lett. 1998, 39, 3873-3876.

11. Camiolo, S.; Gale, P. A.; Ogden, M. I.; Skelton, B. W.; White, A. H., Solid-state and solution studies of biscarboxylate binding by bis-amidinium calix[4]arenes. J. Chem. Soc., Perkin Trans. 2 2001, 1294-1298.

12. Sebo, L.; Schweizer, B.; Diederich, F., Cleft-Type Diamidinium Receptors for Dicarboxylate Binding in Protic Solvents. Helv. Chim. Acta 2000, 83, 80-92.

13. Sebo, L.; Diederich, F.; Gramlich, V., Tetrakis(phenylamidinium)-Substituted Resorcin[4]arene Receptors for the Complexation of Dicarboxylates and Phosphates in Protic Solvents. Helv. Chim. Acta 2000, 83, 93-113.

14. Corbellini, F.; Fiammengo, R.; Timmerman, P.; CregoCalama, M.; Versluis, K.; Heck, A. J. R.; Luyten, I.; Reinhoudt, D. N., Guest Encapsulation and SelfAssembly of Molecular Capsules in Polar Solvents via Multiple lonic Interactions. J. Am. Chem. Soc. 2002, 124, 6569-6575.

15. Corbellini, F.; Di Costanzo, L.; Crego-Calama, M.; Geremia, S.; Reinhoudt, D. N., Guest Encapsulation in a Water-Soluble Molecular Capsule Based on Ionic Interactions. J. Am. Chem. Soc. 2003, 125, 9946-9947.

16. Tanaka, Y.; Katagiri, H.; Furusho, Y.; Yashima, E., A Modular Strategy to Artificial Double Helices. Angew. Chem., Int. Ed. 2005, 44, 3867-3870.

17. Ikeda, M.; Tanaka, Y.; Hasegawa, T.; Furusho, Y.; Yashima, E., Construction of Double-Stranded Metallosupramolecular Polymers with a Controlled Helicity by Combination of Salt Bridges and Metal Coordination. J. Am. Chem. Soc. 2006, 128, 6806-6807.

18. Katagiri, H.; Tanaka, Y.; Furusho, Y.; Yashima, E., Multicomponent Cylindrical Assemblies Driven by Amidinium-Carboxylate Salt-Bridge Formation. Angew. Chem., Int. Ed. 2007, 46, 2435-2439.

19. Nakatani, Y.; Furusho, Y.; Yashima, E., Amidinium Carboxylate Salt Bridges as a Recognition Motif for Mechanically Interlocked Molecules: Synthesis of an Optically Active [2]Catenane and Control of Its Structure. Angew. Chem., Int. Ed. 2010, 49, 5463-5467.

20. Boer, S. A.; Morshedi, M.; Tarzia, A.; Doonan, C. J.; White, N. G., Molecular tectonics: a node-and-linker building block approach to a family of hydrogen bonded frameworks. Chem. Eur. J. 2019, 25, 10006-10012.

21. Morshedi, M.; Ward, J. S.; Kruger, P. E.; White, N. G., Supramolecular frameworks based on $5,10,15,20-$ tetra(4-carboxyphenyl)porphyrins. Dalton Trans. 2018, 47, 783-790.

22. Morshedi, M.; Thomas, M.; Tarzia, A.; Doonan, C. J.; White, N. G., Supramolecular anion recognition in water: synthesis of hydrogen-bonded supramolecular frameworks. Chem. Sci. 2017, 8, 3019-3025.

23. Xing, G.; Bassanetti, I.; Ben, T.; Bracco, S.; Sozzani, P.; Marchiò, L.; Comotti, A., Multifunctional Organosulfonate Anions Self-Assembled with Organic Cations by Charge-Assisted Hydrogen Bonds and the Cooperation of Water. Cryst. Growth Des. 2018, 18, 2082-2092.

24.Xing, G.; Bassanetti, I.; Bracco, S.; Negroni, M.; Bezuidenhout, C.; Ben, T.; Sozzani, P.; Comotti, A., A double helix of opposite charges to form channels with unique CO2 selectivity and dynamics. Chem. Sci. 2019, 10, 730-736.

25. Lewis, C. A.; Wolfenden, R., The Nonenzymatic Decomposition of Guanidines and Amidines. J. Am. Chem. Soc. 2014, 136 (1), 130-136. 
26. For example, the Merck website has the following information about benzamidinium chloride hydrate: "Benzamidine $\mathrm{HCl}$ is sensitive to oxidation. It is recommended to prepare solutions fresh each time in degassed water prior to use. However, frozen aliquots stored under inert gas, to exclude air, may be stable for a short time. Insufficient information is available to assess the shelf-life of a frozen solution."

27. Oxidation of benzamidine/benzamidinium would presumably give the amidoxime; these compounds are often used as pro-drugs for amidines due to the ready reduction of the amidoxime to amidine in vivo. Given this, ready oxidation of the amidine would seem unlikely. Clement, B.; Reduction of N-hydroxylated compounds: amidoximes (N-hydroxyamidines) as pro-drugs of amidines, Drug Metab. Rev. 2002, 34, 565-579.

28. Liang, W.; Carraro, F.; Solomon, M. B.; Bell, S. G.; Amenitsch, H.; Sumby, C. J.; White, N. G.; Falcaro, P.; Doonan, C. J., Enzyme Encapsulation in a Porous Hydrogen-Bonded Organic Framework. J. Am. Chem. Soc. 2019, 141, 14298-14305.

29. We have been able to prepare hydrogen bonded frameworks from anthracenedicarboxylate and tetraamidinium $2^{4+}$ using the TBA salts of the dicarboxylates, see Ref. 20.

30. Boer, S. A.; Yu, L.-J.; Genet, T. L.; Low, K.; Cullen, D. A.; Gardiner, M. G.; Coote, M. L.; White, N. G., What's in an Atom? A Comparison of Carbon and SiliconCentred Amidinium...Carboxylate Frameworks. Chem. Eur. J. 2021, 27, 1768-1776.

31. Simard, M.; Su, D.; Wuest, J. D., Use of hydrogen bonds to control molecular aggregation. Self-assembly of threedimensional networks with large chambers. J. Am. Chem. Soc. 1991, 113, 4696-4698.

32. Fournier, J.-H.; Maris, T.; Wuest, J. D.; Guo, W.; Galoppini, E., Molecular Tectonics. Use of the Hydrogen Bonding of Boronic Acids to Direct Supramolecular Construction. J. Am. Chem. Soc. 2003, 125, 1002-1006.

33. Bassanetti, I.; Bracco, S.; Comotti, A.; Negroni, M.; Bezuidenhout, C.; Canossa, S.; Mazzeo, P. P.; Marchió, L.; Sozzani, P., Flexible porous molecular materials responsive to $\mathrm{CO} 2, \mathrm{CH} 4$ and $\mathrm{Xe}$ stimuli. $J$. Mater. Chem. A 2018, 6, 14231-14239.

34. Uddin, K. M.; Alrawashdeh, A. I.; Henry, D. J.; Warburton, P. L.; Poirier, R. A., Hydrolytic deamination reactions of amidine and nucleobase derivatives. Int. $J$ Quant. Chem. 2020, 120, e26059.

35. Flinn, C.; Poirier, R. A.; Sokalski, W. A., Ab Initio Study of the Deamination of Formamidine. J. Phys. Chem. A 2003, 107, 11174-11181.

36. Albert, A.; Goldacre, R.; Phillips, J., 455. The strength of heterocyclic bases. J. Chem. Soc. 1948, 2240-2249.

37. Cullen, D. A.; Gardiner, M. G.; White, N. G., A three dimensional hydrogen bonded organic framework assembled through antielectrostatic hydrogen bonds. Chem. Commun. 2019, 55, 12020-12023.

38. Thomas, M.; Anglim Lagones, T.; Judd, M.; Morshedi, M.; O'Mara, M. L.; White, N. G., Hydrogen bond-Driven Self-Assembly between Amidinium Cations and Carboxylate Anions: A Combined Molecular Dynamics, NMR Spectroscopy, and Single Crystal X-ray Diffraction Study. Chem. Asian J. 2017, 12, 1587-1597.

39. Nicks, J.; Boer, S. A.; White, N. G.; Foster, J. A., Monolayer nanosheets formed by liquid exfoliation of charge-assisted hydrogen-bonded frameworks. Chem. Sci. 2021.

40. Armarego, W. L. F., Chapter 3 - Purification of Organic Chemicals. In Purification of Laboratory Chemicals (8
Ed.), Armarego, W. L. F., Ed. Butterworth-Heinemann: 2017; pp 95-634.

41. Frisch, M.; Trucks, G.; Schlegel, H.; Scuseria, G. Robb, M.; Cheeseman, J.; Scalmani, G.; Barone, V.; Petersson, G.; Nakatsuji, H.; et al. Gaussian 16. Gaussian, Inc. Wallingford, CT: 2016.

42. Zhao, Y.; Truhlar, D. G., The M06 suite of density functionals for main group thermochemistry, thermochemical kinetics, noncovalent interactions, excited states, and transition elements: two new functionals and systematic testing of four M06-class functionals and 12 other functionals. Theor. Chem. Acc. 2008, 120, 215-241.

43. Marenich, A. V.; Cramer, C. J.; Truhlar, D. G., Universa solvation model based on solute electron density and on a continuum model of the solvent defined by the bulk dielectric constant and atomic surface tensions. J. Phys. Chem. B 2009, 113, 6378-6396.

44. Alecu, I.; Zheng, J.; Zhao, Y.; Truhlar, D. G., Computational thermochemistry: scale factor databases and scale factors for vibrational frequencies obtained from electronic model chemistries. J. Chem. Theory Comput. 2010, 6, 2872-2887.

45. Weigend, F.; Ahlrichs, R., Balanced basis sets of split valence, triple zeta valence and quadruple zeta valence quality for $\mathrm{H}$ to $\mathrm{Rn}$ : Design and assessment of accuracy. Phys. Chem. Chem. Phys. 2005, 7, 3297-3305.

46. Ho, J.; Klamt, A.; Coote, M. L., Comment on the correct use of continuum solvent models. J. Phys. Chem. A 2010, 114, 13442-13444. 